\title{
The Update of an Aerodynamic Wind-Tunnel for Aeroacoustics Testing
}

\author{
Leandro Dantas Santana1, Micael Carmo², Fernando Martini Catalano¹, Marcello A. F. Medeiros
}

\begin{abstract}
This paper describes the update and characterization of a previously pure aerodynamics wind-tunnel into a facility able to simultaneously execute aerodynamics and aeroacoustics testing. It is demonstrated that the application of high-performance acoustic materials on strategic positions of the wind-tunnel circuit and punctual actions can substantially reduce the background-noise level. This paper shows efficient measures which resulted to broadband-noise reduction of up to $5 \mathrm{~dB}$ and practically complete removal of spectral tones. In addition, it is demonstrated that the applied acoustic treatment reduced the turbulence level, measured at the test-section at maximum operational velocity, from the previous $0.25 \%$ level to $0.21 \%$. As a minor penalty, the acoustic treatment reduced the flow velocity in $2 \%$ for the same electric-power input. Finally, the work described in this paper resulted on a wind-tunnel with good flow quality and capacity for aeroacoustics testing.
\end{abstract}

KEYWORDS: Aeroacoustic testing, Wind-tunnel noise, Wind-tunnel acoustic treatment.

\section{INTRODUCTION}

The recent air transportation growth raised concern to authorities and civil institutions regarding its environmental consequences, among them, the noise. In order to regulate this important environmental impact, authorities established noise restrictions to aircraft certification and operations. To comply with these increasingly stringent regulations, the aeronautic industry has been, for decades, developing means to reduce the engine noise. With the current state of the art technology, the aircraft engine reached the same noise level as the airframe. Therefore, regarding noise, the engine optimization is no longer the exclusive preoccupation of the aeronautic industry, now, aeroacoustic development of airframe components also challenges the minds of engineers and aeronautical researchers.

This paper is result of a work-package from the Silent Aircraft project - sponsored by Empresa Brasileira de Aeronáutica (EMBRAER) and Fundação de Amparo à Pesquisa do Estado de São Paulo (FAPESP) with objective to develop critical knowledge on aeroacoustic testing and simulations.

In an international context of building new wind-tunnels for aeroacoustics testing such as the works of Kim et al. (2001), Wickern and Lindener (2000) and Sarradj et al. (2009), or for the adaptation of previously pure aerodynamic wind-tunnel into an aeroacoustic facilities (Remillieux et al., 2008; Künstner et al., 1995), it was decided that upgrading a previously pure aerodynamic facility was the optimal solution for the project requirements and constraints. The chosen wind-tunnel was the closed circuit wind-tunnel LAE-1, situated in the Aerodynamic Laboratory at Escola de Engenharia de São Carlos from the Universidade de São Paulo, Brazil. The work subject of this paper was developed in the period between October 2008 and March 2010.

\footnotetext{
三 1.Escola de Engenharia de São Carlos - São Carlos/SP - Brazil 2. Empresa Brasileira de Aeronáutica - São José dos Campos/SP - Brazil 三 $\quad$ Author for correspondence: Leandro Dantas Santana | Escola de Engenharia de São Carlos | Avenida Trabalhador São Carlense, 400 - Centro | CEP: $13566-590$

Received: 11/30/2013 | Accepted: 02/17/2014
} 
In order to define minimum required levels for noise reduction, it was decided to set, as a target experiment, the measurement of a NACA-0012 trailing-edge airfoil noise at velocity of $30 \mathrm{~m} / \mathrm{s}$. The beamforming technique was used for noise sources identification and possible quantification (Sijtsma and Holthusen, 1999; Brooks and Humphreys, 2006; Dougherty, 2005). Wind-tunnel background-noise is, in this paper, defined as the noise generated by the wind-tunnel running in stable regime and empty testing chamber.

The LAE-1 closed circuit wind-tunnel was designed originally as a $3 / 8$ scale facility prototype of an automotive wind-tunnel to be built in the future. The wind-tunnel was originally built in the period between 1997 and 2002, having as predominant material the naval plywood. Due to the Brazilian automotive industry difficulties in the early 2000s, and the national aeronautic industry rebirth, this previously automotive wind-tunnel, became a multi-task facility with instrumentation mainly focused on aeronautical testing, able to perform a diverse range of industrial and academic tests. Figure 1 presents the drawings of the LAE-1 closed circuit wind-tunnel.

The wind-tunnel test section dimensions are $3.00 \mathrm{~m}$ long, $1.30 \mathrm{~m}$ high and $1.70 \mathrm{~m}$ wide. The maximum design flow speed
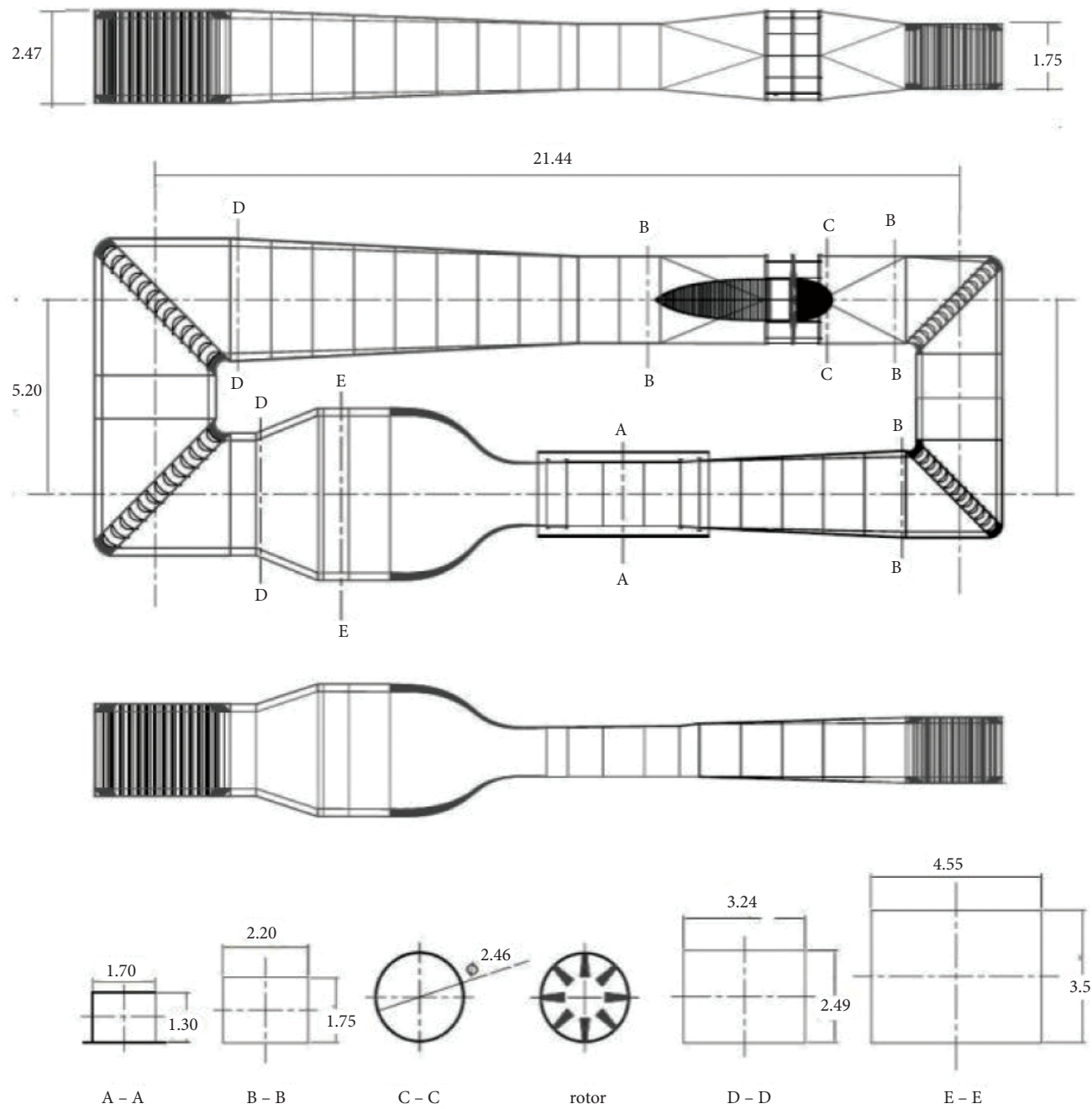

Figure 1. Plan view of the LAE-1 wind-tunnel. 
is $50 \mathrm{~m} / \mathrm{s}$, with turbulence level of $0.25 \%$, nowadays, due to operational safety and components endurance, the maximum speed is limited to $45 \mathrm{~m} / \mathrm{s}$. Its 110-HP-electric motor drives an eight-blade fan, with seven straighteners located downstream the fan. In the flow stabilization section, there are two mesh screens with $54 \%$ porosity, followed by a $1: 8$ contraction cone designed using two $3^{\text {rd }}$ order polynomials, joined at $45 \%$ from the inflection point. The relative low turbulence level, considering the installation of only two screens and no honeycomb, is attributed to the care taken during the design and construction of low angle diffusers, low-drag corner-vanes and high-efficiency rotor blades, optimized using a combination of Computation Fluid Dynamics (CFD) and semi-empirical techniques (Catalano, 2001).

\section{THE BACKGROUND NOISE REDUCTION PROCESS}

The LAE-1 background noise reduction campaign was developed in three phases: a first phase, where conceptual solutions, either innovative or inspired on literature, were multidisciplinary and evaluated as to their efficiency, feasibility and budgetary constraints. This first phase was followed by two steps of effective implementation. In the first step, the effect of pure wall treatment was evaluated, whose results indicated the need of a second step of acoustic treatment, where, in order to achieve the noise reduction target, the addition of an acoustic baffle and fan treatment was implemented.

\section{PRELIMINARY CONCEPTS FOR THE PROJECT}

In order to establish the noise reduction target, it was defined an objective experiment to be done after the wind-tunnel adaptation. The requirements for this experiment were its representativeness of future tests campaign and the detailed availability of results in the literature to be used as a validation data, the self-noise measurement of a NACA-0012 airfoil, carried-out by Brooks et al. (1989), was chosen as an ideal experiment to fulfill those requirements .

An initial wind-tunnel noise assessment was conducted in order to determine the most critical noise condition. From this evaluation, it was found that the flow speed of $31 \mathrm{~m} / \mathrm{s}$ is the most critical condition, due to the existence of fan excited structural resonance. For this reason, this speed was set as reference for the measurements shown in this paper. Figure 2 shows a comparison of the LAE-1 baseline background noise level and the NACA-0012 airfoil noise.

At Fig. 2, the NACA-0012 self-noise was calculated using semi-empirical methods described by Brooks et al. (1989). For these calculations, it was considered a $0.20 \mathrm{~m}$ chord airfoil spanning the wind-tunnel test section, subjected to a $31 \mathrm{~m} / \mathrm{s}$ flow speed and an angle of attack of two degrees.

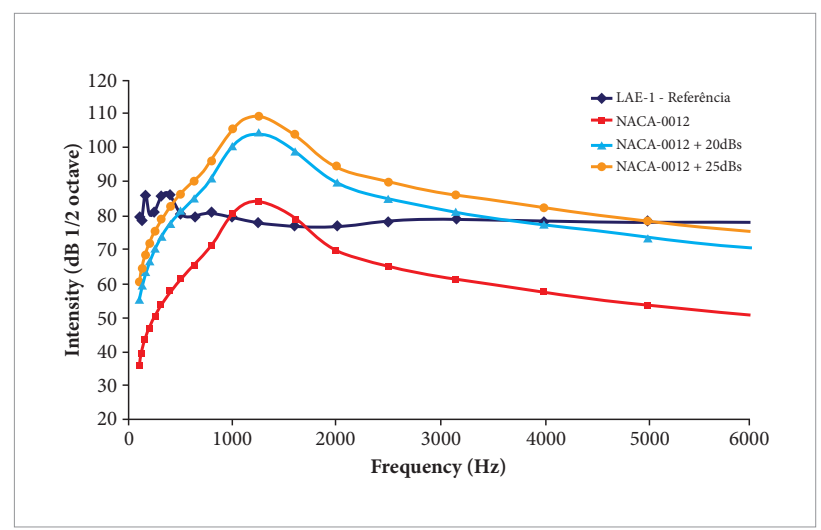

Figure 2. NACA-0012 noise compared with the wind-tunnel background noise.

From Fig. 2, it is noticed that, without post-processing for noise source separation, it is only possible to measure three octave band frequencies, localized from $1 \mathrm{kHz}$ to $1.6 \mathrm{kHz}$. This clearly justifies the need of wind-tunnel background noise reduction in conjunction with the use of a microphone array to increase the measurable bandwidth. For this paper, the post-processing technique considered is the traditional delay-and-sum beamforming. For a microphone array, it is a rule of thumb used to compute the maximum signal to noise ratio (DdB), measurable by an array with $\mathrm{M}$ microphones as proposed by Shin et al. (2007):

$\Delta d B=10 \log _{10} M$

For the current project, it was defined to use an array with $\mathrm{M}=106$ microphones, consequently, it is concluded that it is possible to distinguish a source with an intensity of $20.25 \mathrm{~dB}$ less than the background noise by exclusively using regular post-processing techniques. If advanced decorrelation techniques of beamforming measurements are considered, it is possible to subtract $5 \mathrm{~dB}$ more in relation to the noise level estimated on Eq. 1 (Shin et al., 2007). Finally, it can be concluded that with the gain given by the instrumentation and signal processing, it is 
possible to identify sources $25 \mathrm{~dB}$ less intense than the wind-tunnel background noise level. Adopting these hypotheses, it can be concluded that it is possible to measure a NACA-0012 airfoil noise sources for all the region of the orange line of Fig. 2. In addition to that, after a wind-tunnel background noise reduction of $5 \mathrm{~dB}$, it would be possible to measure the full range of frequencies of interest, from 500 to $8.000 \mathrm{~Hz}$, for the NACA-0012 airfoil.

\section{THE FIRST WIND-TUNNEL NOISE REDUCTION PHASE}

The first phase of acoustic treatment consisted of applying melamine foam on the selected section walls. Several regions of the wind-tunnel were considered for the foam application. Sections with adverse pressure gradient were discarded due to the boundary layer separation risk induced by increasing of the roughness, possible imperfections on the foam superficial finishing, or steps between the foam plates, which may occur on installation or during the operational life of the tunnel. The settling chamber was also discarded due to the risk of negative effects on the flow stabilization. Therefore, the remainder regions $\mathrm{A}$ and $\mathrm{B}$ from Fig. 3 were chosen as the best candidates for foam application.

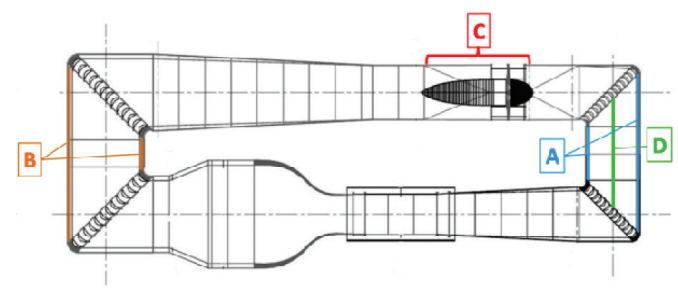

Figure 3. Wind-tunnel regions that received acoustics treatments.

The next step was to define the thickness of the noise absorbent layer. It was performed an analysis of sensitivity for reducing the transversal area, due to the foam thickness on the testing chamber flow velocity. Calculations, made with the help of the wind-tunnel design model, showed that the section reduction on the region of the walls A (see Fig. 3) leads to a very sensible impact on the wind-tunnel flow velocity. The main reason for this is its comparatively high flow speed and, therefore a significant pressure loss. The reduction of the cross-section of the region of the walls B (see Fig. 3) has a minor effect on the wind-tunnel flow velocity, once this area has a lower flow speed and bigger cross-sectional area. To achieve the acceptable margin of $1.5 \%$ of flow velocity reduction, on the testing chamber, it was decided to apply a $2 \mathrm{~cm}$ thick foam on walls $\mathrm{A}$ and $5 \mathrm{~cm}$ thick foam on walls $\mathrm{B}$.

\section{THE SECOND WIND-TUNNEL NOISE REDUCTION PHASE}

In order to increase the noise reduction achieved so far, the second and deeper noise reduction task was conducted.

To reduce the noise at lower frequencies, an acoustic baffle (element D from Fig. 3) was installed between the walls A, dividing the inner sections from the first and second corner vanes. With the installation of this baffle, it was expected a flow speed reduction of no more than $2 \%$, referring to the wind-tunnel baseline conditions. The acoustic baffle construction scheme is shown in Fig.4.

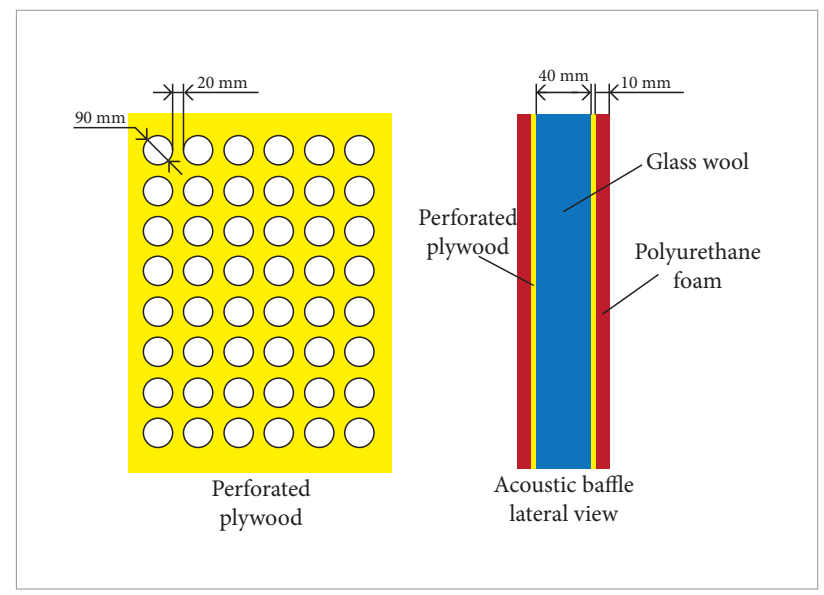

Figure 4. Acoustic baffle construction scheme.

For the design of the baffle, it was considered the feasibility, efficiency and budgetary constraints. This baffle was composed of a sandwich assembly filled with glass wool. The perforated plywood open area was optimized in order to generate a maximum open area to the mechanical strength relationship. The perforated plate was covered with polyurethane foam to assure surface smoothness.

A second action was taken based on the opportunity to improve the wind-tunnel fan performance and, simultaneously, reduce its noise. Due to circularity defects of the metal shield that involves the fan, the tip to wall space varies from $1.5 \mathrm{~cm}$ to $3 \mathrm{~mm}$. This space is known to generate a tip vortex and non-uniform loading to the fan blades, which is a noise source 
(Camargo et al., 2007). To avoid this problem, polyurethane foam was used as filling material in the regions where the gap was greater than $3 \mathrm{~mm}$. The foam leading edge and trailing edge were shaped to guarantee smooth geometric transition. Figure 5 (a) presents the region with greater gap and (b) shows the same region, after the tip treatment, with polyurethane foam.

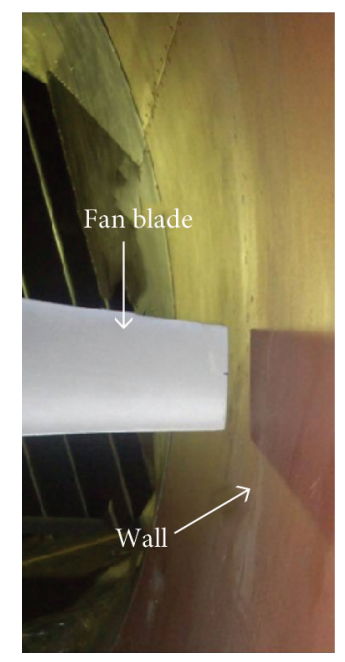

(a)

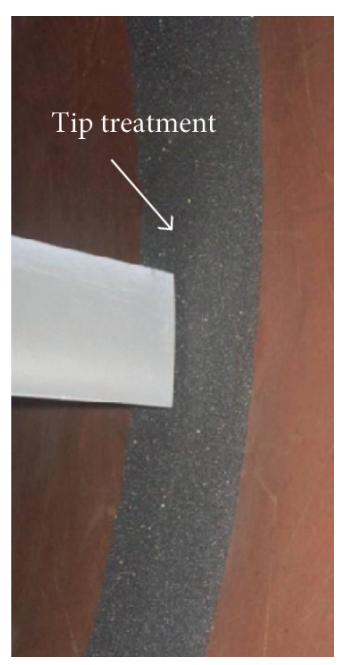

(b)
Figure 5. Region with higher fan tip to wall gap before (a) and after (b) the treatment.

The baseline wind-tunnel noise spectra, measured in the testing chamber, showed the existence of a very intense tone localized at the frequency of $5 \mathrm{kHz}$ and its multiples. The investigation of the origin of this tone and harmonics showed that they were generated by the motor inverter, and they were related to the motor rotational speed controller. The inverter set-up allows changing its carrier frequency to a limit of $10 \mathrm{kHz}$. Considering that higher frequencies are better damped by the medium, the highest achievable frequency was adopted as the carrier frequency for the inverter.

\section{WIND-TUNNEL BACKGROUND NOISE: RESULTS AND DISCUSSION}

Typically the main wind-tunnel noise sources are the walls laminar/turbulent boundary layer, corner vanes, fan trailing edge and the electric motor that drives the fan. This last noise source is mainly related with the speed controller that excites the electrical coil inside the motor producing noise.

It is quite difficult to identify and treat each noise source separately; instead it is more practical and efficient to line the noise propagation path in order to isolate a region of interest, and consequently this approach is adopted in this work.

For low flow speeds, it can be considered that the main wind-tunnel noise source is the sum of the fan and the turbulent boundary layer. Considering this, it was decided to line the region downstream and upstream of the fan, in order to treat both directions of the propagation path of the noise generated by the fan. The upstream distance from the fan to the testing chamber is smaller than the downstream one; therefore, it was preferred to add, as much as possible, acoustic treatment on the region comprised by the walls A (see Fig. 3). In the upstream direction, the settling chamber screens can be considered as a sudden increase of acoustic resistance, which tends to reflect the acoustics waves back, attenuating the noise generated by the fan propagated upstream. To better identify and differentiate the noise sources generated by the fan from the one generated by the flow, the noise spectra were analyzed on three different flow speeds: $15 \mathrm{~m} / \mathrm{s}, 31 \mathrm{~m} / \mathrm{s}$ and $37 \mathrm{~m} / \mathrm{s}$. The results are presented on Figs. 6, 7 and 8 . For low speed $(15 \mathrm{~m} / \mathrm{s})$, it is expected the fan noise to predominate, while for flow speeds up to $37 \mathrm{~m} / \mathrm{s}$ the noise from turbulent boundary layer will be the main source. The velocity of $31 \mathrm{~m} / \mathrm{s}$ is a special point of interest due to the occurrence of a structural resonance induced by the fan rotation.

Analyzing the first phase of noise reductions, regarding the Figs. 7, 8 and 9, it is noticed that for all flow speeds the foam treatment was effective on reducing the noise at frequencies from

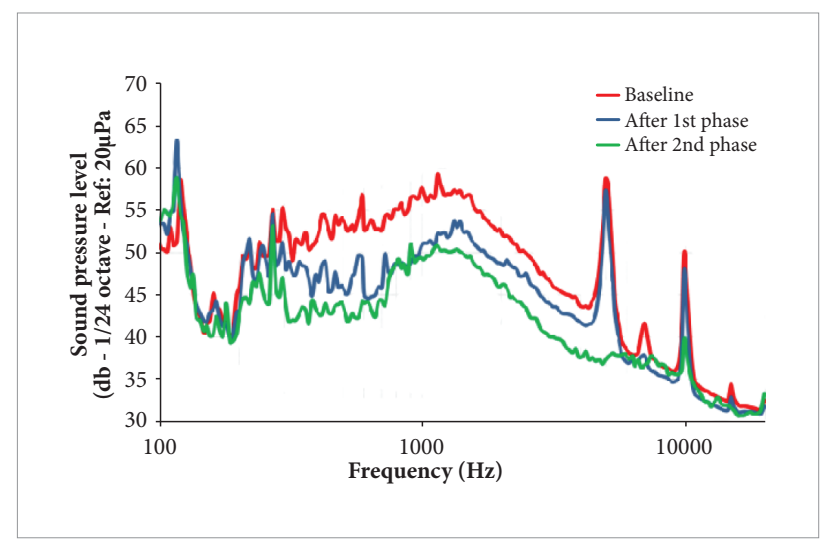

Figure 6. Wind-tunnel noise spectra measured on the testing chamber for a flow velocity of $15 \mathrm{~m} / \mathrm{s}$. 


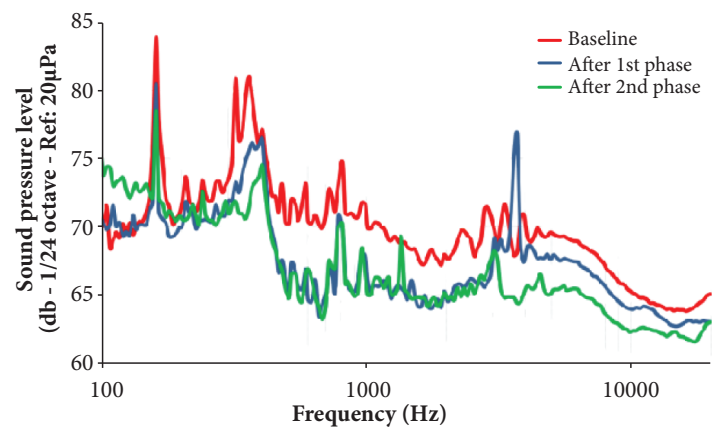

Figure 7. Wind-tunnel noise spectra measured on the testing chamber for a flow velocity of $31 \mathrm{~m} / \mathrm{s}$.

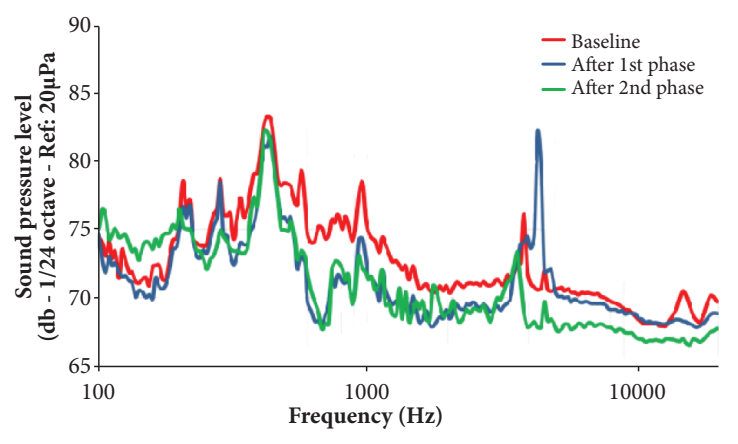

Figure 8. Wind-tunnel noise spectra measured on the testing chamber for a flow velocity of $37 \mathrm{~m} / \mathrm{s}$.

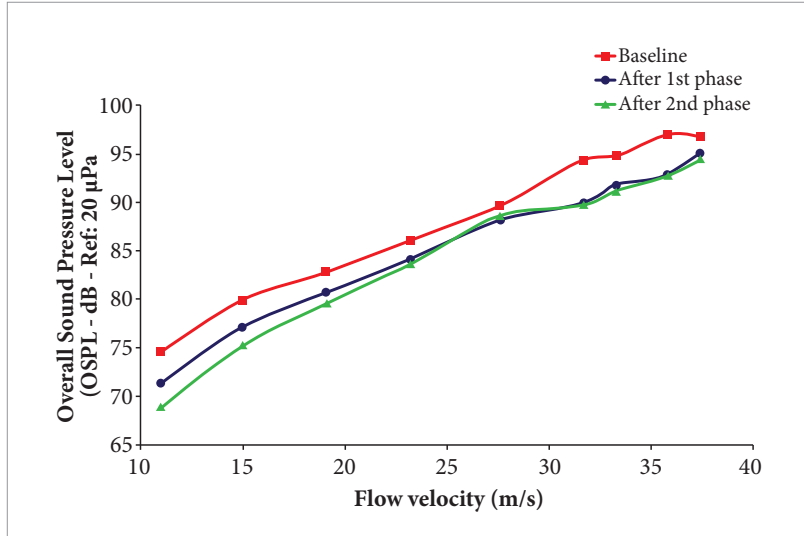

Figure 9. Overall Sound Pressure Level (OSPL) variation with the wind-tunnel flow speed.

$300 \mathrm{~Hz}$ to $4 \mathrm{kHz}$. From Figs. 6 to 8, it is seen that the first phase of noise reduction was effective on absorbing the noise generated by the fan. For lower flow speeds, the noise reduction reached $5 \mathrm{~dB}$, for the frequency of $1 \mathrm{kHz}$. Opposite to that, when the flow speed increases to a higher speed (e.g. $37 \mathrm{~m} / \mathrm{s}$ ), the boundary layer noise becomes a significant noise source, and its reduction reaches $2 \mathrm{~dB}$ for the same frequency. Finally, it can be noticed that the acoustic treatment was very effective in reducing the fan noise at low flow speeds. As a side effect, it can be noticed a noise increase of up to $2 \mathrm{~dB}$ at high frequencies and high flow velocities.

Observing specially Figs. 8 and 9, it is noticed that the final noise treatment phase resulted on undesired noise increment at frequencies below $200 \mathrm{~Hz}$. Even thought all noise level increase is undesired, this side-effect was considered acceptable because it will not affect future noise measurement since this frequency is far below the one of interest for future tests.

An important result in Fig. 6 is the vanishing of the peak at $5 \mathrm{kHz}$ after the second phase of the acoustic treatment. This can be explained by the parameter modification of the inverter that controls the fan rotation. Since this carrier frequency was moved to $10 \mathrm{kHz}$, this tone almost disappeared from the spectrum.

It can be concluded that the first acoustic treatment phase acted mainly at low frequencies while the second one was more effective at high frequencies.

Figure 9 presents the Overall Sound Pressure Level (OSPL) variation as a function of the flow speed. From Fig. 9, it is remarkable that the first phase of noise treatment reduced the OSPL in an average value of $4 \mathrm{~dB}$ for all flow speeds. Opposed to that, the second acoustic treatment phase reduced the OSPL just for flow velocities below $20 \mathrm{~m} / \mathrm{s}$, and had no noticeable effect at high flow speeds.

\section{THE ACOUSTICS TREATMENT EFFECT ON THE FLOW}

The acoustic treatment effect on the flow is verified by the values of the turbulence intensity and the flow velocity. The turbulence was measured with the help of a DANTEC constant temperature hot-wire anemometer system. In this system, a probe model 55P01 was rigidly fixed in the center of the wind-tunnel testing chamber. This probe was calibrated using a DANTEC system described by Bruun (2002).

The hot-wire anemometer data was acquired using a sampling ratio of $6400 \mathrm{~Hz}$ during 5 seconds. The measured turbulence raw data was processed with in-house software that calculates the turbulence intensity and auto-power-spectra. A parametric study showed that the 
calculation of the wind-tunnel turbulence, free of structural vibration and electrical noise influence, requires the use of a band-pass filter, which filters frequencies outside the $3 \mathrm{~Hz}$ and $1.000 \mathrm{~Hz}$ range.

Figure 10 shows the evolution of the turbulence intensity with the velocity measured in the testing chamber.

Figure 10 shows that the turbulence grows with velocity up to, approximately, $19 \mathrm{~m} / \mathrm{s}$, reaching a constant level, for velocities up to $30 \mathrm{~m} / \mathrm{s}$, and, consecutively, decays for higher velocities. This behavior is present in all phases of the acoustics treatment. The explanation to this behavior is based on the fact that this wind-tunnel was designed for a $50 \mathrm{~m} / \mathrm{s}$ flow, meaning that, as the velocity increases, the flow passes from a laminar/low-turbulence to an "on design" condition, where the constant pitch blade reaches its optimum point. Since, for high velocities, the turbulence eddies, with largest length scales, have their characteristic length reduced, when compared to low velocities, which propitiates a more effective viscous dissipation. As a macro-effect of this, there is a measurable decreasing in the working section turbulence level as shown in Fig. 10.

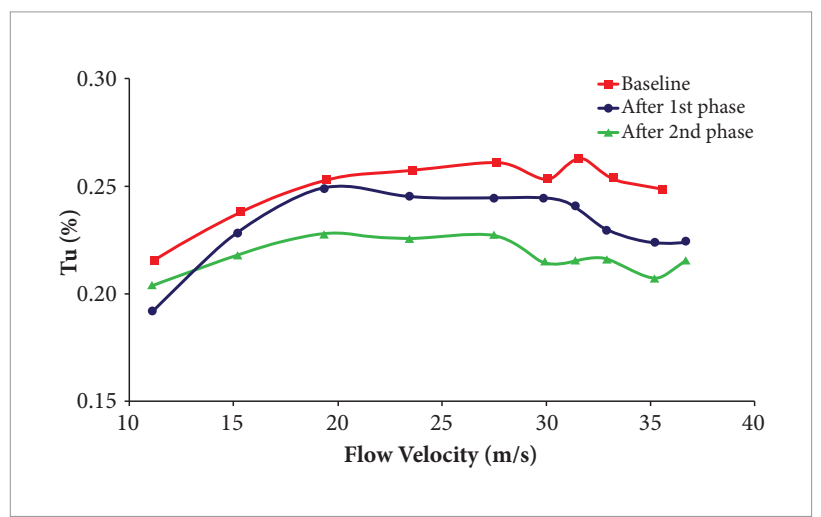

Figure 10. Wind-tunnel turbulence measured on the testing chamber.

A second point, coming from Fig. 10 analysis, is the fact that the acoustic treatment resulted to a positive effect on the wind-tunnel turbulence intensity levels. This is explained by the reduction of the acoustic noise, known as an excitation source on the non-linear instabilities mechanisms that lead the flow to turbulence. In addition to this is the fact that, for high Reynolds numbers, the statistics of small eddies is universally and uniquely determined by the viscosity and the rate of energy dissipation, not related to the noise, in such way that the turbulence generation has been decreased but the dissipation rate has been kept constant.

The turbulence spectrum is presented in Figs. 11 and 12.
It is desirable, for good quality wind-tunnels, that its turbulence spectrum is free of tones. It is noticed from Figs. 11 and 12 that the acoustic treatment does not introduce any effect on the turbulence spectra.

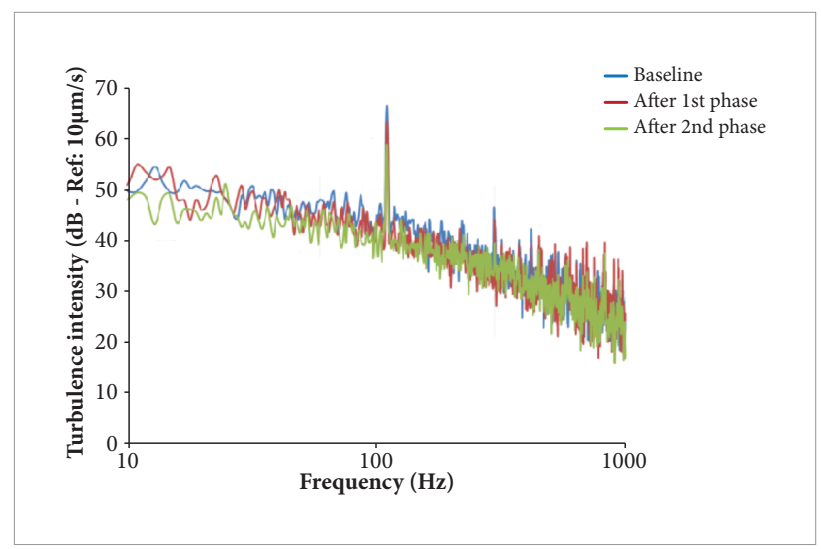

Figure 11. Wind-tunnel turbulence spectrum measured after background noise reduction process for a flow speed of $20 \mathrm{~m} / \mathrm{s}$.

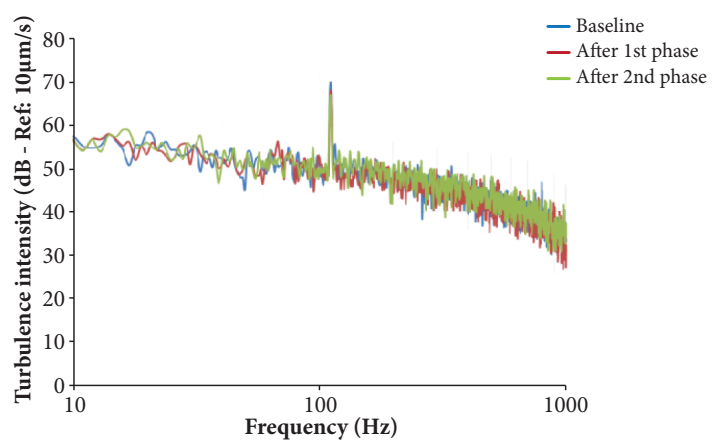

Figure 12. Wind-tunnel turbulence spectrum measured after background noise reduction process for a flow speed of $31 \mathrm{~m} / \mathrm{s}$.

The last analysis is the influence of the acoustic treatment to the flow velocity, for the same input power. The electric power input for the motor that drives the wind-tunnel fan, will be calculated based on the manufacturer information that a constant torque is kept with the rotational speed variation. Consequently, the flow velocity is a direct function of the pressure losses, and it is possible to compare the flow velocity reduction after the noise treatment phases. As previously mentioned, the foam installation on the walls increased its local velocity due to the cross-section reduction. Therefore, a slightly increase to the pressure loss, at the treated sections, are expected with the 
related decrease of the test section velocity. Figure 13 shows the acoustic treatment phases effect on the test section velocity.

Analyzing Fig. 13 results, it is seen that the flow velocity reduction was in agreement with the expected within the two phases of noise treatment. The second acoustic treatment phase caused the most important flow speed reduction. This fact can, mainly, be attributed to the hydraulic diameter reduction, caused by the baffle installation. Considering that the pressure loss is proportional to the inverse of the hydraulic diameter, reducing the hydraulic diameter in 2 times implies on a sectional pressure loss of 8 times. Since section B pressure loss is small,

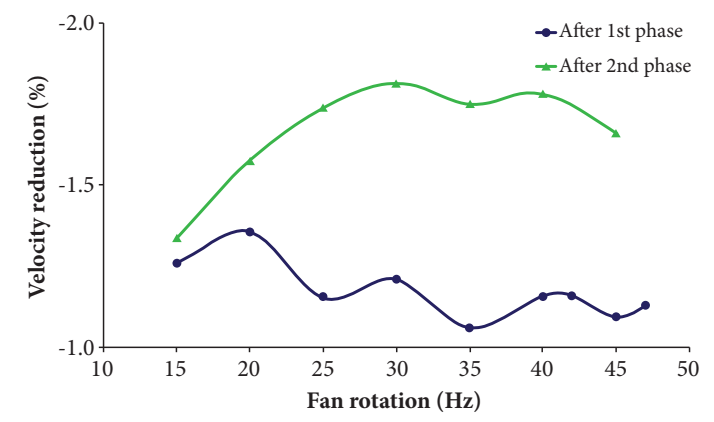

Figure 13. Wind-tunnel flow velocity reduction due the acoustic treatment. compared to the rest of the wind-tunnel, a minor effect on the total wind-tunnel velocity reduction is expected.

\section{CONCLUSIONS}

The present paper shows the process of background noise reduction for the LAE-1 wind-tunnel. This process was divided into two main phases, where, in a first phase, the effect acoustic treatment on strategic parts of the wind-tunnel circuit was evaluated. Results showed that this treatment was more effective at frequencies ranging from 400 to $4 \mathrm{kHz}$. A second phase, complementary to the first, acted mainly on frequencies above $4 \mathrm{kHz}$. These two noise treatment phases resulted on a wind-tunnel background noise reduction of up to $5 \mathrm{~dB}$, and a desirable turbulence level reduction from the original $0.25 \%$ to $0.21 \%$, with no addition of tones on the turbulence spectra. The minor drawback of this work was the reduction of $2 \%$ in the flow speed, considering a constant electric power input.

\section{ACKNOWLEDGEMENTS}

The authors acknowledge FAPESP and EMBRAER for the financial support for this project.

\section{REFERENCES}

Brooks, T.F. and Humphreys, W.M., 2006, "A Deconvolution Approach for the Mapping of Acoustics Sources (DAMAS) Determined from Phased Microphone Arrays", Journal of Sound and Vibration, Vol. 294, pp. 856-879.

Brooks, T.F., Pope, D.S. and Marcolini, M.A., 1989, "Airfoil Self-Noise and Prediction", NASA Reference Publication 1218.

Bruun, H.H., 2002, "Hot-Wire Anemometry - Principles and Signal Analysis", $2^{\text {nd }}$ Edition, Oxford Science Publications.

Camargo, H., Remillieux, M., Burdisso, R., Crede, E. and Devenport, W., 2007, "The Virginia Tech Stability Wind Tunnel from an aerodynamic into an aeroacoustic facility", 19 th $^{\text {th }}$ International Congress on Acoustics, Madrid.

Catalano, F.M., 2001, "The new closed circuit wind tunnel of the aircraft laboratory of University of São Paulo", 16 $6^{\text {th }}$ Brazilian Congress of Mechanical Engineering, Vol. 6, pp. 306-312.

Dougherty, R.P., 2005, "Extension of DAMAS and benefits and limitations of deconvolution in beamforming", 11 th $A$ AIA/CEAS Aeroacoustics Conference.

Kim M., Lee J., Kee J. and Chang J., 2001, "Hyundai Full Scale Aero-acoustic Wind Tunnel”, SAE Technical Papers, 2001-01-0629.
Künstner R., Potthoff J. and Essers U., 1995, "The Aero-Acoustic Wind Tunnel of Stuttgart University", SAE Technical Papers, 950625.

Remillieux M.C., Crede E.D., Camargo H.E., Burdisso R.A., Devenport W.J. and Rasnick M., Van Seeters P., Chou A., 2008, "Calibration and Demonstration of the New Virginia Tech Anechoic Wind Tunnel", 14th AIAA/CEAS Aeroacoustics Conference, AIAA 2008-2911.

Sarradj E., Fritzsche C., Geyer T. and Giesler J., 2009, "Acoustic and aerodynamic design and characterization of a small-scale aeroacoustic wind tunnel", Applied Acoustics, Vol. 70, pp. 1073-1080.

Shin, H.C., Grahan, W.R., Sijtsma, P., Andreou, C. and Faszer, A.C., 2007, "Implementation of a Phased Microphone Array in a ClosedSection Wind Tunnel", AIAA Journal, Vol. 45, No. 12.

Sijtsma, P. and Holthusen, H., 1999, "Source Location by Phased Array Measurements in Closed Wind Tunnel Test Sections", AIAA-99-1814.

Wickern G. and Lindener N., 2000, "The Audi Aeroacoustic Wind Tunnel: Final Design and First Operational Experience”, SAE Technical Papers, 2000-01-0868. 